\title{
TNAP limits TGF- $\beta$-dependent cardiac and skeletal muscle fibrosis by inactivating SMAD2/3 transcription factors
}

Benedetta Arnò*1,2, Francesco Galli*1, Urmas Roostalu ${ }^{1,3}$, Bashar Aldeiri ${ }^{1,4}$, Tetsuaki Miyake $^{5}$, Alessandra Albertini ${ }^{1,6}$, Laricia Bragg ${ }^{1}$, Sukhpal Prehar ${ }^{7}$, John C. McDermott $^{5}$, Elizabeth J. Cartwright ${ }^{7}$ and Giulio Cossu ${ }^{1}$

${ }^{1}$ Division of Cell Matrix Biology \& Regenerative Medicine, Faculty of Biology, Medicine and Health, University of Manchester, Manchester, M13 9PT, UK ${ }^{2}$ Medicines Discovery Catapult, Mereside, Alderley Edge SK104TG, UK ${ }^{3}$ Gubra Hørsholm Kongevej 11B 2970 Hørsholm, Denmark

${ }^{4}$ King's College Hospital, Denmark Hill, London, SE5 9RS, UK ${ }^{5}$ Department of Biology, York University, Toronto, ON, M3J 1P3, Canada ${ }^{6}$ TIGET-HSR, Ospedale San Raffele, Via Olgettina 60. 20132 Milan, Italy

${ }^{7}$ Division of Cardiovascular Sciences, Manchester Academic Health Science Centre, The University of Manchester, Manchester, M13 9PT, UK.

* These authors contributed equally to the work.

Running title: TNAP inhibits SMAD activity

Summary statement: This paper shows that tissue non-specific alkaline phosphatase negatively regulates TGF- $\beta$ signalling and may represent a mechanism to limit fibrosis through SMAD dephosphorylation.

\section{Correspondence to:}

Prof. Giulio Cossu

Division of Cell Matrix Biology \& Regenerative Medicine

Faculty of Biology, Medicine and Health, University of Manchester.

Manchester Academic Health Science Centre

Michael Smith Building, D.4316

Oxford Road. M13 9PL Manchester, UK

Tel: +44 (0) 1613062526

E-mail: giulio.cossu@manchester.ac.uk

\section{Abstract}


Fibrosis is associated with almost all forms of chronic cardiac and skeletal muscle diseases. The accumulation of extracellular matrix impairs the contractility of muscle cells contributing to organ failure. Transforming growth factor beta (TGF- $\beta$ ) plays a pivotal role in fibrosis, activating pro-fibrotic gene programs via phosphorylation of SMAD2/3 transcription factors. However, the mechanisms that control dephosphorylation of SMAD2/3 have remained poorly characterized. Here we show that tissue non-specific alkaline phosphatase (TNAP) is highly upregulated in hypertrophic hearts and in dystrophic skeletal muscles, and the abrogation of TGF- $\beta$ signalling in TNAP positive cells reduces vascular and interstitial fibrosis. We show that TNAP co-localizes and interacts with SMAD2. TNAP inhibitor MLS-0038949 increases SMAD2/3 phosphorylation, while TNAP overexpression reduces SMAD2/3 phosphorylation and the expression of downstream fibrotic genes. Overall our data demonstrate that TNAP negatively regulates TGF- $\beta$ signalling and likely represents a mechanism to limit fibrosis.

\section{Introduction}

Fibrosis accompanies many chronic diseases and is a common response to injury. It is characterized by excessive production and accumulation of collagen and other extracellular matrix (ECM) components, cellular dysfunction and loss of tissue architecture that eventually lead to organ failure (Ueha et al., 2012). Fibrosis can affect many organs, including heart and skeletal muscle, and has become a major cause of death in the developed world.

Fibrosis is an integral component of most cardiac pathological conditions and can be associated with cardiomyocyte death (Frangogiannis, 2012), pressure or volume overload (Berk et al., 2007), hypertrophic cardiomyopathy (Kania et al., 2009) and toxic insults (Bernaba et al., 2010).

Skeletal muscle fibrosis accompanies aging, in which case gradual muscle loss leads to the accumulation of adipose tissue and ECM (Alnaqeeb et al., 1984; Wood et al., 2014). Fibrosis occurs early in congenital muscular dystrophies and impairs muscle function and regeneration (Serrano and Munoz-Canoves, 2017; Tedesco and Cossu, 2012). In both cardiac and skeletal muscle, fibrosis increases the stiffness of the tissue, 
thereby directly impairing muscle cell contraction.

The molecular pathways involved in fibrosis are well known and common for the two organs. Transforming Growth Factor beta (TGF- $\beta$ ), in addition to being a major morphogen during development, is one of the main signaling molecules initiating fibrosis and is secreted by many cell types in the injured tissue. Its activity is controlled by proteolytic cleavage of a precursor, eventually bound to inhibitory proteins and subsequently released by proteases. Active TGF- $\beta$ binds to the serine threonine protein kinases receptors (termed TGF- $\beta$ receptor type I and type II) and induces the phosphorylation and activation of SMAD2/3 transcription factors (also known as receptor regulated SMADs or R-SMADs) (Heldin et al., 1997; Zi et al., 2012). The phosphorylation of R-SMADs triggers their association with SMAD4, leading to their nuclear translocation, where they control the transcription of profibrotic genes. Finally, the dephosphorylation of R-SMADs promotes their exit from the nucleus and the end of the signaling (Bruce and Sapkota, 2012). As a central regulator of a number of physiologically important processes TGF $\beta$ signaling is highly regulated. Cellular susceptibility is determined by receptor endocytosis via clathrin and caveolin dependent pathways (Di Guglielmo et al., 2003). Depletion of TGF $\beta$ ligand defines the transcriptional response and is achieved by TGF $\beta$ binding to the cell surface or its cellular uptake (Clarke et al., 2009). The duration and temporal dynamics of ligand availability influence downstream signaling response, as repeated pulses of TGF $\beta$ can lead to long-term sustained response ( $\mathrm{Zi}$ et al., 2011). Several posttranslational modifications are capable of regulating R-SMAD activity. These include ubiquitinylation (Dupont et al., 2012; Dupont et al., 2005; Episkopou et al., 2001; Lin et al., 2000; Zhu et al., 1999), acetylation (Gronroos et al., 2002), parpylation (Lonn et al., 2010), sumoylation (Miles et al., 2008) and phosphorylation at different serine residues (Kretzschmar et al., 1997). Rapid inactivation of R-SMADs can be achieved by dephosphorylation. However, to date only one R-SMAD phosphatase, PPM1A (Protein Phosphatase 1A), has been identified for the TGF- $\beta$ pathway (Lin et al., 2006). Identification of new R-SMAD phosphatases would enable efficient attenuation of pro-fibrotic signaling in acute and chronic diseases.

Tissue Non Specific Alkaline Phosphatase (TNAP) is an enzyme widely expressed in many organs. It is involved in bone mineralization and mutations in the TNAP gene have been associated with hypophosphatasia, a rare inherited disorder, characterized 
by defective bone mineralization (Mornet et al., 2001). Recently TNAP has been associated with vascular calcification (Romanelli et al., 2017; Sheen et al., 2015) and cardiac fibro-calcification (Herencia et al., 2015). Its role in fibrosis and in the context of TGF- $\beta$ signaling has not been addressed.

In the present study we demonstrate that TNAP negatively regulates TGF- $\beta$ signaling pathway by regulating the level of phosphorylation of SMAD 2/3. We show that TNAP is highly induced in hypertrophic hearts and dystrophic skeletal muscle and the abrogation of TGF- $\beta$ signaling in TNAP positive cells reduces vascular and interstitial fibrosis. TNAP interacts with SMAD2 and its overexpression decreases SMAD phosphorylation and the expression of downstream fibrotic genes.

\section{Results}

We previously established TNAP expression in skeletal muscle and demonstrated that its high activity marks perivascular cells (Dellavalle et al., 2007). In contrast, we found that TNAP is more widely expressed in healthy mouse heart. We detected alkaline phosphatase activity mainly in the interstitium (Figure 1a,b) but also in cardiomyocytes (Figure 1c). At higher resolution (Figure 1d) AP activity co-localized both with endothelial (VE-Cadherin + ) and perivascular (NG2+) cells and also extended outside of the small vessels (fig. 1d). Of the three AP isoforms, Intestinal, Embryonic and Non Specific, only the latter is expressed in the heart at any developmental stage examined (Fig. 1e). When TNAP-Cre ${ }^{\text {ERT }}$ mice (Dellavalle et al. 2011) were crossed to NGZ reporter mice, LacZ activity was detected in many areas of the heart (Figure 1f). Additional examples of TNAP localization in adult healthy heart are shown in Supplementary Figure 1.

Angiotensin II infusion increases TNAP expression in cardiomyocytes and cardiac fibroblast in vivo.

We next analysed changes in TNAP activity in response to fibrosis. We used a model of Angiotensin II-induced cardiac hypertrophy, which is known to cause fibrosis after few days (Crowley et al., 2006). We implanted subcutaneous mini-pumps releasing Angiotensin II (Ang II) $(2.8 \mathrm{mg} / \mathrm{kg}$ per day) for two weeks in 10 weeks old C57/BL6J mice. We analysed the hearts of treated mice for the presence of hypertrophy and 
fibrosis. As expected, the treatment with Ang II caused cardiomyocytes hypertrophy and led to an increase in Tenascin $\mathrm{C}$ positive areas compared with mice treated with saline solution (Sham) (Supplementary Fig. 2a-i). Moreover, the expression of the fibrotic genes Fibronectin1, Tenascin C, Sma2, Vimentin and Collagen1a2 was significantly upregulated in Ang II treated mice compared with the control (Supplementary Fig. 2j-p).

We took advantage of this disease model to analyse the expression of Tnap. Interestingly, we found a significant increase in the number of $\mathrm{TNAP}^{+}$cells in hypertrophic hearts in comparison to the control (Fig. 2a-c; $n=5$ for each group). Moreover, we detected an upregulation of Thap expression by RT-qPCR (Figure 2d). In order to understand which cell types express TNAP in physiological and pathological conditions, we stained the heart sections for TNAP and Laminin, Vimentin and PECAM, which allow identification of cardiomyocytes basal lamina, cardiac interstitial and endothelial cells respectively, and using confocal microscopy counted the number of double positive cells in a $77 \mathrm{~mm}^{2}$ area. We confirmed that all three cells types analysed expressed TNAP in normal heart (TNAP/PECAM ${ }^{+}$cells $16.6 \pm 6 \%$, TNAP/Laminin ${ }^{+}$cells $26 \pm 5.4 \%$, TNAP/Vimentin $^{+} /$PECAM $^{-}$cells $27 \pm$ $5.6 \%, \mathrm{n}=3$ mice, mean \pm s.d.). Remarkably, in the Ang II treated mice the number of cells expressing TNAP significantly increased in all three different cell populations $\left(\mathrm{TNAP}^{+} / \mathrm{PECAM}^{+}\right.$cells $30.5 \pm 4.1 \% ; \mathrm{TNAP}^{+} /$Laminin $^{+}$cells $42.4 \pm 1.5 \%$, $\mathrm{TNAP}^{+} /$Vimentin $^{+} / \mathrm{PECAM}^{-}$cell;s $49.3 \pm 6 \%, \mathrm{n}=3$ mice, mean \pm s.d., $\mathrm{P}<0.001$, twotailed t-test) (Fig. 2e-m). These data prove that in hypertrophic hearts TNAP is significantly up regulated in cardiac myocytes, endothelial cells and interstitial cells.

However, it is important to notice that, under normal condition only a minority of cells in the heart express TNAP and even if this number almost doubles in Ang treated animal, it remains confined to less than half of total cardiac cells.

The abrogation of TGF- $\beta$ signaling in TNAP positive cells reduces fibrosis in the heart and skeletal muscle

Since the increased number of TNAP $^{+}$cells is preferentially localised in Tenascin $\mathrm{C}$ positive regions (Fig. 2a,b, k, 1), we reasoned that $\mathrm{TNAP}^{+}$cells might have a role in the regulation of fibrosis upon Ang II treatment. TNAP is widely expressed in many different cells so that a cardiac specific knock out would be technically very challenging in this context as Cre should be driven by al least three (cardiac, 
endothelial and interstitial) different promoters. Therefore, to prove that TNAP expressing cells are in fact involved in cardiac fibrosis, despite being a minority of total cardiac cells, we inactivated TGF- $\beta$ signalling specifically in TNAP positive cells. To achieve this goal we took advantage of an inducible conditional knockout $\operatorname{Tnap}^{\text {cre }}$; Tgf $\beta r 2$ floxed mouse (Chytil et al., 2002; Dellavalle et al., 2011). This strain is characterized by the inactivation, upon tamoxifen injection, of TGF- $\beta$ Receptor 2 (TGF-ßR2) in TNAP expressing cells. We first verified by immunofluorescence whether $\mathrm{TNAP}^{+}$cells express TGF- $\beta \mathrm{R} 2$ and found that virtually all $\mathrm{TNAP}^{+}$cells are also positive for TGF- $\beta$ R2, both in Sham and Ang II treated mice (Fig. 3a, b). We then injected the Tnap ${ }^{\text {cre }} ; T g f \beta r 2^{\mathrm{fl} / \mathrm{fl}}$ transgenic mice with $100 \mathrm{mg} / \mathrm{kg}$ of tamoxifen (TAM) once a day for 5 days; at day 7 we implanted subcutaneous mini-pumps releasing $2.8 \mathrm{mg} / \mathrm{kg}$ per day of Ang II for 2 weeks (Fig. 3c). We verified Cre recombination efficiency on the total heart of the Tnap ${ }^{c r e} ; \operatorname{Tg} \beta \beta r 2^{\mathrm{fl} / \mathrm{fl}}$ mice by RT-qPCR for the exon 4 of the $T g f-\beta r 2$, the exon excised by Cre recombinase (Chytil et al., 2002), and found approximately $50 \%$ reduction in its expression in $\operatorname{Tnap}^{\text {cre }} ; \operatorname{Tg} f \beta r 2^{\mathrm{fl} / \mathrm{fl}}$ compared to control (Fig. 3d). We confirmed this recombination efficiency by counting the number of TNAP/tdTomato double positive cells over the total number of TNAP $^{+}$cells in the Tnap ${ }^{\text {cre }}$;Rosa26-tdTomato mice. Injection of control oil, did not modify the expression of TNAP.

We next quantified the area of fibrosis in $\operatorname{Tnap}^{\text {cre }} ; \operatorname{Tg} \beta \beta r 2^{\mathrm{fl} / \mathrm{fl}}$ Sham treated mice, $T g f \beta r 2^{\mathrm{fl} / \mathrm{fl}}$ treated with Ang II and Tnap ${ }^{c r e} ; T g f \beta r 2^{\mathrm{fl} / f 1}$ treated with Ang II. We found a strong reduction of interstitial and vascular fibrosis in the Tnap ${ }^{\text {cre }} ; \operatorname{Tg} f \beta r 2^{\mathrm{fl} / \mathrm{fl}}$ Ang II treated mice in comparison with the $T g f \beta r 2^{f l f f l}$ treated with Ang II (Fig. 3e-1). This result was confirmed by Azan-Mallory staining and by IF analysis, showing reduced expression of Collagen $1 \mathrm{a} 2$ and MMP1 in $\operatorname{Tnap}^{\text {cre }} ; \operatorname{Tgf\beta r} 2^{\mathrm{fl} / \mathrm{fl}}$ Ang II treated mice in comparison with the Tgf $\beta r 2^{f l f l}$ treated with Ang II (Supplementary Fig. 4a-i). We analysed cardiac hypertrophy in $T N A P^{\mathrm{cre}} T g f \beta R I^{\mathrm{f} / \mathrm{fl}}$ mice treated with Ang II compared with the control by calculating the heart weight/ body weight ratio and by measuring the area of cardiomyocytes, but we found no difference in cell size and in overall hypertrophy within the two groups (Fig. $3 \mathrm{~m}-\mathrm{q}$ ), indicating that the reduction of fibrosis is not accompanied by a reduction in hypertrophy. We next characterized the expression of fibrotic genes by RT-qPCR in the three sample groups and found a 
significant reduction in Collagen $1 a 2$ and Vimentin expression in the Tnap ${ }^{\text {cre }} ; \operatorname{Tg} f-\beta r 2$ flffl mice treated with Ang II compared with the controls (Fig. 3r,s), while Sma2 expression did not change (Fig. 3t). Moreover, also immunostaining with antibodies against collagen 1 and MMP1 showed a dramatic reduction of areas of fibrosis, as also confirmed by Azan-Mallory staining (Supplementary figure 4). These data prove that TNAP is specifically expressed and upregulated in cells with active TGF- $\beta$ signalling that underlie cardiac fibrosis. It is remarkable that a 50\% reduction of expression in a minority of the cardiac cell population leads to a dramatic decrease in the level of fibrosis, suggesting a specific role of TNAP+ cells in regulating fibrosis.

Since it has been previously shown that TNAP is up regulated in dystrophic muscles (Diaz-Manera et al., 2012) we asked whether the abrogation of TGF- $\beta$ signalling in $\mathrm{TNAP}^{+}$cells in dystrophic mice could reduce skeletal muscle fibrosis. We took advantage of the alpha-sarcoglycan deficient (Sgca-null) mice, a model for LimbGirdle Muscular Dystrophy 2D (Duclos et al., 1998) that develop severe fibrosis after 2 months of age. We generated a triple transgenic strain by crossing the Sgca null mice with the $\operatorname{Tnap}^{\text {cre }} ; T g f-\beta r 2^{f l f l}$ mouse. We injected 6-7 days old pups with tamoxifen for three days and sacrificed at 2 months old (Fig.4a). We measured the recombination efficiency of Cre recombinase by RT-qPCR and western blot (Fig.4, b,c) and found it to be $50 \%$. We next analysed the extent of fibrosis by measuring the percentage of Tenascin $\mathrm{C}$ positive regions and found a significant decrease in fibrosis in the Tibialis Anterior (TA), the Gastrocnemius (GA) and the Diaphragm (DIA) of the Sgca null Tnap $^{\text {cre }} ; T g f-\beta r 2^{\text {flfl }}$ mice compared with the Sgca null controls (Fig.4 d-g). We analysed the level of Collagen1a2 by immunofluorescence (Fig.4h) and the expression level of Collagen1a2, Sma2 and Vimentin by RT-qPCR (Fig.4 i-k). We observed a significant reduction of their expression in the Sgca null Tnap ${ }^{\text {cre }} ; \operatorname{Tgf}-\beta r 2^{\text {flfl }}$ mice compared with the Sgca null controls. In order to reveal whether the reduction of fibrosis in the triple transgenic mice is sufficient to improve muscle strength and function, we measured muscle grip strength by placing mice on an upside down grid (Bonetto et al., 2015). Wild-type mice started to explore the environment and spent little time in the same location. In contrast Sgca knockout mice spent $26 \%$ of the total time without moving, which importantly decreased to only $10 \%$ in the triple transgenic mice (Fig.4l) ( $\mathrm{n}=4$ each group). These data suggest that the reduction in fibrosis is associated with improved skeletal muscle function. Overall the data so far demonstrate that cells that express TNAP in fibrotic cardiac and skeletal muscle are of pivotal 
significance in the TGF- $\beta$-dependent development of the pathology as inhibition of TGF- $\beta$ signalling in these cells is sufficient to limit fibrosis.

TNAP inhibits SMAD2/3 phosphorylation and limits the expression of downstream fibrotic genes

Since we obtained similar results in cardiac and skeletal muscle models of fibrosis, we hypothesized that TNAP may have a role in the regulation of TGF- $\beta$ signalling and that this role is conserved in both tissues. Being a phosphatase, TNAP could be involved in the dephosphorylation of p-SMAD2/3 and have thereby a regulatory role in the transcription of fibrotic genes. In order to test our hypothesis we first verified if TNAP and p-SMAD2/3 co-localize within the cell. We stained sections for TNAP and p-SMAD2/3 and saw that both of them partially co-localise in the peri-nuclear region (Fig. 5a). We confirmed their co-localization also in vitro. We transfected $\mathrm{C} 2 \mathrm{C} 12$ skeletal myogenic cells with EYFP-SMAD2 and mCherry-TNAP plasmids and confirmed that the two proteins co-localize in intracellular vesicular compartments around the nucleus (Fig. 5b). Interestingly TNAP and SMAD2 co-localization was present in both Sham and Ang II treated mice (Fig. 5a). We found that TNAP not only co-localizes with SMAD2 but also physically interacts with it. We proved this by using Proximity Ligation Assay (PLA) (Shah et al., 2017) (Fig. 5c) and coimmunoprecipitation on C2C12 transfected with Myc-TNAP (Supplementary Fig. 5).

Our results show that endogenous SMAD2 interacts with Myc-TNAP. Notably, the TNAP-SMAD2 interaction not only occurs upon TGF- $\beta$ stimulation, but also, at lower level, under control conditions. In order to understand if this interaction has a functional relevance on TGF- $\beta$ signalling we treated cardiac fibroblast with TGF- $\beta 1$ (5ng/ml) and the specific TNAP inhibitor MLS-0038949 (Crowley et al., 2006) (200nM) for 1 hour and analysed SMAD2/3 phosphorylation by western blot. The cells treated with TGF- $\beta 1$ and TNAP inhibitor showed a significant increase in SMAD2/3 phosphorylation compared with cells treated with only TGF- $\beta 1$ (Fig.5d) ( $n=3$ independent experiments), suggesting that the blockade of TNAP leads to enhanced TGF- $\beta$ signalling. To provide further evidence for TNAP regulation of SMAD2/3 activity we overexpressed plasmid encoding for Myc-TNAP in C2C12 skeletal muscle cells and stimulated the cells with TGF- $\beta 1(5 \mathrm{ng} / \mathrm{ml})$. We chose this cell line because it has no detectable TNAP expression (Fig. 5e). We verified that the 
plasmid was functional by staining $\mathrm{C} 2 \mathrm{C} 12$ with a functional assay for AP (Fig. 5e,f). Upon TGF- $\beta 1$ stimulation we detected a decrease in SMAD2/3 phosphorylation in Myc-TNAP overexpressing cells compared with the GFP control (Fig. 5g). Inhibition of SMAD2/3 phosphorylation was not dramatic because on average approximately 20$30 \%$ of $\mathrm{C} 2 \mathrm{C} 12$ cells are transiently transfected. Together these data prove that TNAP is capable and in itself sufficient to limit SMAD2/3 phosphorylation. We next analysed the expression of fibrotic genes downstream p-SMAD2/3 by RT-qPCR and observed that Fibronectin1, Collagenla2 and Tenascin $C$ expression were downregulated in Myc-TNAP overexpressing cells compared with the control (Fig. $5 \mathrm{~h}$ ), indicating that TNAP induced dephosphorylation of p-SMAD2/3 is sufficient to limit fibrotic genes transcription. Taken together these data indicate that TNAP regulates SMAD2/3 phosphorylation levels and is a direct attenuator of cellular profibrotic signaling pathways.

\section{Discussion}

Despite ever increasing understanding of the molecular processes that trigger fibrosis across different organs there are only few therapies available and most of them only indirectly target fibrotic processes (Rockey et al., 2015). TGF- $\beta 1$ binding to the receptors on the plasma membrane leads to the phosphorylation of R-SMADs, their translocation into the nucleus and transcription of pro-fibrotic genes. Given the importance of TGF- $\beta$ signaling and the phosphorylation of R-SMADs in fibrosis, the identification of phosphatases, able to switch off the TGF- $\beta$ pathway, has been of interest in the past ten years since they could also be targets for anti-fibrotic drugs. Nevertheless, until now, only one phosphatase, PPM1A, has been identified (Lin et al., 2006). Here we show that TNAP is able to dephosphorylate SMAD2/3 and consequently limit the transcription of pro-fibrotic genes.

An abundant literature exists on TNAP function in bone development and calcification (Byon et al., 2008; Millan, 2013); yet the role of TNAP in the heart has only been partly elucidated. TNAP overexpression has recently been associated with increased cardiac fibrosis and vascular calcification. Sheen et al. demonstrated that the induced expression of TNAP in vascular smooth muscle cells is sufficient to cause medial vascular calcification (Sheen et al., 2015). Similarly Romanelli and colleagues showed 
that TNAP overexpression in vascular endothelium in mice leads to arterial calcification and subsequent coronary atherosclerosis (Romanelli et al., 2017). These studies described the effects of sustained TNAP overexpression, but the role of TNAP under physiological levels of expression has not been addressed. Indeed, it is counterintuitive that tissues where calcification is exclusively pathological, have maintained TNAP expression during evolution. This suggests that TNAP may also play beneficial roles in striated muscle that is eventually overridden by sustained fibrotic stimuli; however this role has thus far remained unknown. Here we analysed two different models of fibrosis: rapid-onset cardiac fibrosis induced by the hypertensive molecule Ang II, and chronic skeletal muscle fibrosis in the Sgca null mice. We confirm earlier evidence showing that TNAP is upregulated in tissue fibrosis (Herencia et al., 2015) (Gan et al., 2014), but also show here that the number of cells expressing TNAP increases in both heart and skeletal muscle. Furthermore, as the abrogation of TGF- $\beta$ signaling in TNAP positive cells dramatically reduces vascular and interstitial fibrosis, we can conclude that TNAP is actively expressed in cells driving tissue fibrosis. Since in the heart, not only interstitial/perivascular cells but also endothelial cells and cardiomyocytes participate to the process (though likely to a minor extent), it is interesting to note that TNAP has a similar pattern of expression, being more abundant in interstitial/perivascular cells but also present in the other cell types of the heart.

TGF- $\beta$ signaling relies on trafficking of activated phosphorylated R-SMAD proteins from the plasma membrane to the nucleus (Chen, 2009; Hough et al., 2012; Nakao A, 1997). SMAD2/3 inactivation during this process would enable a cell to rapidly limit the expression of pro-fibrotic genes even in the presence of TGF- $\beta$ secreted in the inflammatory tissue environment. Here we show that TNAP inhibition enhances SMAD2/3 phosphorylation whereas TNAP overexpression has the opposite effect. We demonstrate that TNAP interacts with SMAD2. Our data collectively prove that TNAP is an efficient inhibitor of SMAD2/3 and limits SMAD-dependent transcription of profibrotic genes. Intriguingly, TNAP interacts with SMAD2 even in cells that are not exposed to TGF- $\beta 1$. These results demonstrate that TNAP likely has a housekeeping function during normal tissue growth and homeostasis, which explains its basal level expression in cardiac and skeletal muscle. In addition to the molecular mechanism described here, TNAP may also indirectly affect the activity of numerous phosphorylation-dependent pathways as this enzyme is known to regulate the level of 
cytoplasmic inorganic phosphate (Pi) ( Hessle et al., 2002).

We show here that the ubiquitously expressed TNAP is an essential regulator of SMAD2/3-dependent TGF- $\beta$ signaling in physiological conditions and in tissue fibrosis. These results provide a novel insight into the mechanisms that control the expression of extracellular matrix genes and may lead to the development of novel therapies for fibrosis.

\section{Material and methods}

\section{Animals}

Mice were maintained in pathogen-free conditions at Manchester University animal facility and fed standard rodent diet. Animal studies were performed according to the United Kingdom Animals (Scientific Procedures) Act 1986 and approved by the University of Manchester Ethics Committee. Angiotensin experiments were approved under Home Office license no. 40/3625 and no. P3A97F3D1. All the other experiments were approved under licence no.707435 . Sgca null mice (Duclos et al., 1998), Tnap ${ }^{\text {cre }}$ mice (Dellavalle et al., 2011) and Tgfbr $2^{\text {floxflox }}$ (Chytil et al., 2002) mice were backcrossed onto C57BL/6 mice (Charles River Laboratories Inc, Wilmington, MA, USA) and were genotyped as previously described (Dellavalle et al., 2011). Mice were culled by administration of isoflurane and consequent cervical dislocation at appropriate time points. Hearts and muscles were collected in ice-cold PBS and then embedded in glue or OCT inclusion media. Samples were stored at $80^{\circ} \mathrm{C}$ before processing.

\section{Osmotic Minipump Infusion of Angiotensin II and Tamoxifen administration}

In order to generate cardiac hypertrophy, Angiotensin II (Sigma Aldrich, St. Louis, MO, USA Cat. No. A9525) $(2.8 \mathrm{mg} / \mathrm{kg} /$ day $)$ or vehicle $\left(\mathrm{ddH}_{2} \mathrm{O}\right)$ was administrated to 10 week old wild type (wt) and transgenic male mice via osmotic mini-pumps (1002, Alzet, Cupertino, CA, USA) implanted subcutaneously. Briefly, the mice were anaesthetized with isoflurane (5\% induction; 2-3\% maintenance) in oxygen, using a small nose cone attached to a modified Bane circuit. The skin on the dorsal surface of the animal was shaved with the clipper and sterile scissors were used to make a 0.5 $\mathrm{cm}$ horizontal incision. Subcutaneous tissue was spread using a haemostat to create a 
pocket in which the minipump was inserted. The incision was closed with absorbable suture (5-0 Maxon). After the surgery the mice received $0.1 \mathrm{mg} / \mathrm{kg}$ of buprenorphine and were allowed to recover before being returned to the home cage. Hearts were isolated and analyzed for cardiac hypertrophy following 14 days of Angiotensin II infusion. In order to induce the expression of the Cre recombinase in the null Tnap ${ }^{\text {cre }}$ $T g f \beta r 2^{f l f l}$ and $\mathrm{SgCa}^{-/}$null Tnap ${ }^{\text {cre }} \mathrm{Tg} f \beta r 2^{f l f f l}$, Tamoxifen (Sigma Aldrich, Cat. No. T5648) was dissolved in corn oil (Sigma Aldrich, Cat. No. C8267) and injected at the following concentrations and time points: $0.3 \mathrm{mg} / \mathrm{mouse}$ in 6 days old pups once a day for 3 consecutively days and $3 \mathrm{mg} /$ mouse in 10 weeks old mice once a day for 5 consecutively days.

Grip test

The four limb-hanging test (also known as Kondziella's inverted screen test) (Bonetto et al., 2015) represents a method to assess muscle strength using all four limbs and to determine the general condition over time. In this study, we modified this method to improve its variability and consistency. Briefly we placed the mice upside down on a grid $(50 \mathrm{~cm} \times 30 \mathrm{~cm})$ and we counted the number of seconds in which the mice were not moving on the grid, over a total period of $50 \mathrm{sec}$ each mice. We calculated the resting time on the grid as the average of 3 different tests for each mouse, and we analysed 4 mice per each group.

\section{PLA and Immunofluorescence}

PLA was performed according to the manufacturer's instructions using the Duolink In Situ Orange Kit Goat/Rabbit (Sigma Aldrich, Cat. No. DUO92106). Immunofluorescence was performed as previously described (Arno et al., 2014). Briefly sections $(5 \mu \mathrm{m})$ were fixed in $4 \%$ Paraformaldehyde (Sigma Aldrich, Cat. No. P6148) in PBS, pH 7.2 for $20 \mathrm{~min}$; then washed 3 times, 5 min each, in PBS and the blockage of non-specific binding was done by using the following blocking buffer: PBS 1X/Fetal bovine serum (FBS) 10\%/Bovine serum albumin (BSA) 1 $\mathrm{mg} / \mathrm{ml} /$ Triton $\mathrm{X} 100 \mathrm{0.1 \%}$, for $1 \mathrm{~h}$ at room temperature. In all steps slides were kept in humidified chambers. For the TNAP staining the sections were additionally fixed with methanol-acetone for $10 \mathrm{~min}$. Antibodies were diluted in blocking buffer and incubated at $+4^{\circ} \mathrm{C}$ overnight as suggested by manufacturer's instructions. The following day, sections were rinsed in PBS for $5 \mathrm{~min}, 3$ times, and fluorescent 
secondary antibodies, (Alexafluor conjugated,Thermo Fisher Scientific) diluted in blocking buffer were applied accordingly manufacturer's instructions. Slides were washed 3 times in PBS for $5 \mathrm{~min}$ and incubated in DAPI (Sigma Aldrich, Cat. No.10236276001) for nuclei counterstaining. The following antibodies were used: goat $\alpha$-TNAP (Santa Cruz Biotechnology, Dallas, Texas, USA Cat. No. c-23430) 1:100; rabbit $\alpha$-TNAP (Abgent, Suzhou city, China. Cat. No. AP1474C) 1:100; rat $\alpha-$ PECAM (Dev. Studies Hybridoma Bank) 1:3; rabbit $\alpha$-Laminin (Santa Cruz Biotechnology Cat. No. sc-17810) 1:100: chicken $\alpha$-GFP (Abcam, Cambridge,UK Cat. No. ab13970) 1:500; rabbit $\alpha$-collagen1a2 (Merck Millipore, Billerica, MA, USA) 1:75; rabbit $\alpha$-Tenascin C (Merck Millipore Cat. No. AB19013) 1:150; chicken $\alpha$-Vimentin (Novus biologicals, Littleton, Colorado, USA Cat. No. NB300-223) 1:300; rabbit $\alpha$-TGF- $\beta$ RII (Novus biologicals Cat. No. NB100- 91994) 1:100; rabbit $\alpha$-SMAD2 (Cell Signalling, Danvers, Massachusetts, USA Cat. No. D43B4) 1:100; rabbit $\alpha$-pSMAD2/3 (Cell Signalling Cat. No. D27F4) 1:100; rabbit $\alpha$-Ki67 (Abcam Cat. No. ab15580) 1:200. Appropriate fluorophore-conjugated secondary antibodies (Alexa-Fluor $488 \mathrm{~nm}, 594 \mathrm{~nm}$ and $647 \mathrm{~nm}$, Molecular Probes) were applied accordingly manufacturer' instruction. Nuclei were visualized using DAPI. For the detection of TNAP activity, the Red Alkaline Phosphatase (Red AP) Substrate Kit (VECTOR Laboratories, Peterborough,UK SK-5100) was used according to manufacture instructions. Light (Zeiss Axio Imager M2, with x5, x10 and x20 objectives) and confocal (Leica, SP5 with x40 and x63 objectives) microscopy was performed to analyze tissue and cell staining. For confocal imaging, pictures were acquired at $1 \times$ line average and $3 \times$ frame average on a single confocal plane. Analysis was performed by using Zeiss ZEN 2 software and Adobe Photoshop CS5 Version 12.0x64 software. Quantification of Tenascin $\mathrm{C}^{+}$regions in hearts and skeletal muscles were done by using ImageJ 2.0.0-rc-9.

\section{Cell culture}

C2C12 cells from European Collection of Authenticated Cell Cultures, Public Health England (Porton Down, UK) were cultured in DMEM (Gibco, ThermoFisher, Waltham, MA, USA), supplemented with 1\% L-Glutamine, 10\% fetal bovine serum (FBS), 1\% penicillin-streptomycin (ThermoFisher Cat. No. 15140122). Cells were transfected with Lipofectamine 2000 (Thermo Fisher Scientific Cat. No. 11668027) according to manufacture instructions. The following plasmids were used for 
transfection: pEGFP-N1 (Clontech Cat. No. 6085-1), pCDNA3.1 N-Myc-TNAP and pCDNA3-mCherry TNAP. In details Smad2/TNAP ORF was RT-PCR amplified from mouse cDNA. PCR products were inserted into EcoRI/XhoI of the EYFP/mCherry/myc-pcDNA3 vectors. Cardiac fibroblasts were obtained from neonatal and adult C57B1/6 mice. Mice were killed by cervical dislocation and their hearts were rapidly removed. The hearts were then mashed with scalpels and digested with $10 \square \mathrm{ml}$ collagenase solution $(120 \square \mathrm{mg}$ collagenase A (Roche Cat. No. 10103 578001 ) and $12 \square \mathrm{mg}$ protease (Sigma Cat. No. 10165921001) dissolved in $80 \square \mathrm{ml}$ PBS solution) at $37 \square{ }^{\circ} \mathrm{C}$ for $15 \square \mathrm{min}$, for five times. Cells were collected after each digestion and the collagenase was deactivated by addition of 50\% FBS. The fibroblasts were centrifuged for $5 \square \mathrm{min}$ at $220 \square \mathrm{g}$. The cell pellet was resuspended in $10 \square \mathrm{ml}$ ACF media (80\% DMEM, 20\% FBS, 1\% penicillin/streptomycin and $1 \%$ nonessential amino acids). Fibroblasts were then plated in $10 \square \mathrm{ml}$ delta-NUNC tissue culture plates (ThermoFisher Cat. No. 150318) overnight. The next day, the media was removed and replaced with $10 \square \mathrm{ml} \mathrm{ACF} \mathrm{media.} \mathrm{C2C12} \mathrm{and} \mathrm{cardiac} \mathrm{fibroblasts}$ were serum starved for $24 \mathrm{~h}$ before adding medium containing $5 \mathrm{ng} / \mathrm{ml}$ recombinant TGFß1 for 2 days (R\&D Systems, Minneapolis, USA Cst. No. Cat. No. 7666-MB005 ).

\section{Western Blot and Immunoprecipitation}

Hearts and skeletal muscles from wt, TNAP ${ }^{\text {cre }}$ TGF- $\beta$ RII ${ }^{\mathrm{fl} / \mathrm{fl}}$ and alpha-sarcoglycan null TNAP ${ }^{\text {cre }}$ TGF- $\beta$ RII ${ }^{\mathrm{fl} / \mathrm{fl}}$ and controls were homogenized with the homogenizer SHM1 (Stuart Equipment Stone, Staffordshire, UK Cat. No. 1171631) in RIPA lysis buffer $(50 \mathrm{mM}$ Tris $\mathrm{HCl}, \mathrm{pH} 8.0,150 \mathrm{mM} \mathrm{NaCl}, 1 \% \mathrm{NP}-40,0.5 \%$ sodium deoxycholate, $0.1 \%$ SDS, supplemented with Phosphatase and Protease inhibitor cocktail, Sigma Aldrich Cat. No. PCC 1010). Cold lysis buffer (RIPA) was added into the wells after removing the media and washing the cells with PBS. The cells were scraped into sterile, pre-cooled tubes. The samples were incubated (with rotation) for 30-60 min at $4^{\circ} \mathrm{C}$. Soluble proteins were quantified with Bradford Protein Assay Kit (Bio-Rad Cat. No. 5000006). $50 \mu \mathrm{g}$ of protein extract was run in SDS-polyacrylamide gel electrophoresis (PAGE) and subsequently blotted on a nitrocellulose membrane. For immunoprecipitation experiments $\mathrm{C} 2 \mathrm{C} 12$ cells were collected in lysis buffer (50mM Tris- $\mathrm{HCl} \mathrm{pH} 7.8,150 \mathrm{mM} \mathrm{NaCl}, 1 \mathrm{mM} \mathrm{CaCl}_{2}$ and $1 \%$ Triton X-100) supplemented with Protease inhibitor cocktail (Sigma-Aldrich Cat. No.P8340). 1 
$\mathrm{mg} / \mathrm{ml}$ of pre-cleared lysates were incubated with anti-Smad2 (Cell Signalling, Cat. No. D43B4) at dilution 1:50 or the negative control rabbit IgG in lysis buffer with rotation overnight at $+4{ }^{\circ} \mathrm{C}$. The samples were then incubated with protein $\mathrm{A}$ magnetic beads (Merc Millipore Cat. No. LSKMAGA10) for $1 \mathrm{~h}$ at $+4{ }^{\circ} \mathrm{C}$ (with rotation) and the immuno-complexes were detected by western blot. The following primary antibodies were used: goat $\alpha$-Myc (1:1000, Abcam Cat.No. ab9132); rabbit $\alpha$-TGF-BRII (Novus biologicals Cat. No. NB100- 91994) 1:500, mouse $\alpha$-Vinculin (Santa Cruz Biotechnology Cat. No. H300) 1:6000, rabbit $\alpha$-SMAD2 (Cell Signalling Cat. No. D43B4) 1:1000; rabbit $\alpha$-pSMAD2/3 (Cell Signalling Cat. No. D27F4) 1:1000. Secondary antibodies (Dako Donkey anti-goat P0449; Dako Goat anti-rabbit P0448) were incubated for $1 \mathrm{~h}$ at RT, and signals were revealed using Millipore ECL kit (Cat. No. WBKLS0500). For quantitative measurement, blots were analyzed with ImageJ 2.0.0-rc-9, normalizing band intensities to Vinculin levels.

\section{Real time and standard RT-PCR}

Total RNA from heart, skeletal muscle and cells was extracted by homogenizing the samples in Trizol (Thermo Fisher Scientific, Cat. No. 15596018) reagent following the standard manufacturer's procedure. Chloroform was added to the samples that were incubated for $15 \mathrm{~min}$ at room temperature and then centrifuged at $12000 \mathrm{~g}$ for 15 min. The aqueous layer was mixed with isopropanol, incubated for $10 \mathrm{~min}$ and centrifuged for $10 \mathrm{~min}$ at $12000 \mathrm{~g}$. $75 \%$ of ethanol was added and the samples were centrifuged at $12000 \mathrm{~g}$ for $15 \mathrm{~min}$. After the elimination of ethanol the RNA was dissolved in 50 ul of H20. DNase (Thermo Scientific, Cat. No. 18068015) digestion was done on all the samples. RNA was quantified with Nanodrop 2000 and equalized to same concentration before cDNA synthesis. cDNA synthesis was performed using ThermoScript RT-PCR System (Thermo Scientific, Cat. No. K1622) according to the manufacturer's instructions in final volume of $20 \mu 1$. RT-qPCR was carried out using FastStart Essential DNA Master Mix (Cat. No. 06402712001; Roche diagnostics GmbH, Mannheim, Germany). RT-qPCR was performed in five biological replicate, using standard dilution series on every plate. Samples were normalized by using the housekeeping genes Gapdh and Rlp19 with the following primers:

Gapdh F: 5'-AGGTCGGTGTGAACGGATT-3', Gapdh ： R: 5'TGTAGACCATGTAGTTGAG-3' and 
Rpl19 F: 5'-ATGAGTATGCTCAGGCTACAGA-3', Rpl19 R: 5'GCATTGGCGATTTCATTGGTC-3’.

Specific primers were used for gene expression analysis:

Tenascin $\quad$ : $\quad$ F5' ${ }^{\prime} \quad$ ACGGCTACCACAGAAGCTG 3'; R5' ATGGCTGTTGTTGCTATGGCA 3'

Fibronectinl: $\quad$ F5' ${ }^{\prime} \quad$ TTCAAGTGTGATCCCCATGAAG $\quad$ 3'; $\quad$ R5' CAGGTCTACGGCAGTTGTCA 3'

Vimentin: $\quad$ F5'- $\quad$ CGGCTGCGAGAGAAATTGC $\quad 3^{\prime}$; $\quad$ R5' CCACTTTCCGTTCAAGGTCAAG 3'

TGF- $\beta r 2 \quad$ exon4/5: GACCTCAAGAGCTCTAACATCC3'; R5'-

CTAGAACTTCCGGGGCCATG3'

TGF- $\beta r 2: \quad$ F5'-CCGCTGCATATCGTCCTGTG3'; R5'AGTGGATGGATGGTCCTATTACA3'

Sma2: $\quad$ F5' -5'CCCAGACATCAGGGAGTAATGG3';

R5'TCTATCGGATACTTCAGCGTCA3'

Colla2:

F5'GGAGAGAGGAGTCGTTGGAC-3';

\section{R5'GTTCACCCTTCACACCCTGT3'}

\section{Statistics.}

Data are expressed as the mean \pm standard deviation (SD) or standard error of the mean (S.E.M.) of independent experiments. Comparisons were made using the unpaired t-test. Statistical tests were carried out using PRISM6.0e (GraphPad Software, La Jolla, CA). A p-value less than 0.05 was considered statistically significant.

\section{Competing interests}

Authors declare no conflict of interest.

\section{Funding}

B. Arnò was supported by British Heart Foundation (PG/14/1/30549). U. Roostalu was supported by Biotechnology and Biological Sciences Research Council Anniversary Future Leader Fellowship (BB/M013170/1). J. McDermott and T. Miyake were supported by Canadian Institutes of Health Research (CIHR). E. 
Cartwright was supported by British Heart Foundation (PG/14/1/30549). G. Cossu was supported by British Heart Foundation (PG/14/1/30549), MRC (MR/P016006/1), Duchenne Parent Project (Italy), the GOSH-Sparks Charity V4618.

\section{References}

Alnaqeeb, M.A., Al Zaid, N.S., and Goldspink, G. (1984). Connective tissue changes and physical properties of developing and ageing skeletal muscle. J Anat 139 ( Pt 4), 677-689.

Arno, B., Grassivaro, F., Rossi, C., Bergamaschi, A., Castiglioni, V., Furlan, R., Greter, M., Favaro, R., Comi, G., Becher, B., et al. (2014). Neural progenitor cells orchestrate microglia migration and positioning into the developing cortex. Nature communications 5, 5611 .

Berk, B.C., Fujiwara, K., and Lehoux, S. (2007). ECM remodeling in hypertensive heart disease. The Journal of clinical investigation 117, 568-575.

Bernaba, B.N., Chan, J.B., Lai, C.K., and Fishbein, M.C. (2010). Pathology of lateonset anthracycline cardiomyopathy. Cardiovascular pathology : the official journal of the Society for Cardiovascular Pathology 19, 308-311.

Bonetto, A., Andersson, D.C., and Waning, D.L. (2015). Assessment of muscle mass and strength in mice. BoneKEy reports 4, 732 .

Bruce, D.L., and Sapkota, G.P. (2012). Phosphatases in SMAD regulation. FEBS letters 586, 1897-1905.

Byon, C.H., Javed, A., Dai, Q., Kappes, J.C., Clemens, T.L., Darley-Usmar, V.M., McDonald, J.M., and Chen, Y. (2008). Oxidative stress induces vascular calcification through modulation of the osteogenic transcription factor Runx2 by AKT signaling. J Biol Chem 283, 15319-15327.

Chen, Y.G. (2009). Endocytic regulation of TGF-beta signaling. Cell research 19, 5870.

Chytil, A., Magnuson, M.A., Wright, C.V., and Moses, H.L. (2002). Conditional inactivation of the TGF-beta type II receptor using Cre:Lox. Genesis (New York, NY : 2000) 32, 73-75.

Clarke, D.C., Brown, M.L., Erickson, R.A., Shi, Y., and Liu, X. (2009). Transforming growth factor beta depletion is the primary determinant of Smad signaling kinetics. Mol Cell Biol 29, 2443-2455.

Crowley, S.D., Gurley, S.B., Herrera, M.J., Ruiz, P., Griffiths, R., Kumar, A.P., Kim, H.-S., Smithies, O., Le, T.H., and Coffman, T.M. (2006). Angiotensin II causes hypertension and cardiac hypertrophy through its receptors in the kidney. Proceedings of the National Academy of Sciences of the United States of America 103, 1798517990.

Dellavalle, A., Maroli, G., Covarello, D., Azzoni, E., Innocenzi, A., Perani, L., Antonini, S., Sambasivan, R., Brunelli, S., Tajbakhsh, S., et al. (2011). Pericytes resident in postnatal skeletal muscle differentiate into muscle fibres and generate satellite cells. Nature communications 2, 499.

Dellavalle, A., Sampaolesi, M., Tonlorenzi, R., Tagliafico, E., Sacchetti, B., Perani, L., Innocenzi, A., Galvez, B.G., Messina, G., Morosetti, R., et al. (2007). Pericytes of 
human skeletal muscle are myogenic precursors distinct from satellite cells. Nat Cell Biol 9, 255-267.

Di Guglielmo, G.M., Le Roy, C., Goodfellow, A.F., and Wrana, J.L. (2003). Distinct endocytic pathways regulate TGF-beta receptor signalling and turnover. Nat Cell Biol $5,410-421$.

Diaz-Manera, J., Gallardo, E., de Luna, N., Navas, M., Soria, L., Garibaldi, M., Rojas-Garcia, R., Tonlorenzi, R., Cossu, G., and Illa, I. (2012). The increase of pericyte population in human neuromuscular disorders supports their role in muscle regeneration in vivo. The Journal of pathology 228, 544-553.

Dupont, S., Inui, M., and Newfeld, S.J. (2012). Regulation of TGF-beta signal transduction by mono- and deubiquitylation of Smads. FEBS Lett 586, 1913-1920.

Dupont, S., Zacchigna, L., Cordenonsi, M., Soligo, S., Adorno, M., Rugge, M., and Piccolo, S. (2005). Germ-layer specification and control of cell growth by Ectodermin, a Smad4 ubiquitin ligase. Cell 121, 87-99.

Episkopou, V., Arkell, R., Timmons, P.M., Walsh, J.J., Andrew, R.L., and Swan, D. (2001). Induction of the mammalian node requires Arkadia function in the extraembryonic lineages. Nature 410, 825-830.

Duclos, F., Moore S.A., Venzke D.P., Hrstka, R.S.,. Crosbie, R.S., Lebakken, C.S., Ettinger, A.J. , van der Meulen R., Leland K.E., Lim, Sanes J.S., Davidson, B.L., Faulkner, A.S, Williamson, R and Campbell K.P. (1998). Progressive Muscular Dystrophy in a-Sarcoglycan-deficient Mice. J. Cell Biol. 142, 1461-1468.

Frangogiannis, N.G. (2012). Regulation of the inflammatory response in cardiac repair. Circulation research 110, 159-173.

Gan, X.T., Taniai, S., Zhao, G., Huang, C.X., Velenosi, T.J., Xue, J., Urquhart, B.L., and Karmazyn, M. (2014). CD73-TNAP crosstalk regulates the hypertrophic response and cardiomyocyte calcification due to alphal adrenoceptor activation. Mol Cell Biochem 394, 237-246.

Gronroos, E., Hellman, U., Heldin, C.H., and Ericsson, J. (2002). Control of Smad7 stability by competition between acetylation and ubiquitination. Mol Cell 10, 483493.

Heldin, C.H., Miyazono, K., and ten Dijke, P. (1997). TGF-beta signalling from cell membrane to nucleus through SMAD proteins. Nature 390, 465-471.

Herencia, C., Rodriguez-Ortiz, M.E., Munoz-Castaneda, J.R., Martinez-Moreno, J.M., Canalejo, R., Montes de Oca, A., Diaz-Tocados, J.M., Peralbo-Santaella, E., Marin, C., Canalejo, A., et al. (2015). Angiotensin II prevents calcification in vascular smooth muscle cells by enhancing magnesium influx. European journal of clinical investigation 45, 1129-1144.

Hessle, L., Johnson, K.A., Anderson, H.C., Narisawa, S., Sali, A., Goding, J.W., Terkeltaub, R., and Millan, J.L. (2002). Tissue-nonspecific alkaline phosphatase and plasma cell membrane glycoprotein-1 are central antagonistic regulators of bone mineralization. Proc Natl Acad Sci U S A 99, 9445-9449.

Hough, C., Radu, M., and Dore, J.J. (2012). Tgf-beta induced Erk phosphorylation of smad linker region regulates smad signaling. PloS one 7, e42513.

Kania, G., Blyszczuk, P., and Eriksson, U. (2009). Mechanisms of cardiac fibrosis in inflammatory heart disease. Trends in cardiovascular medicine 19, 247-252.

Kretzschmar, M., Doody, J., and Massague, J. (1997). Opposing BMP and EGF signalling pathways converge on the TGF-beta family mediator Smad1. Nature 389, 618-622. 
Lin, X., Duan, X., Liang, Y.Y., Su, Y., Wrighton, K.H., Long, J., Hu, M., Davis, C.M., Wang, J., Brunicardi, F.C., et al. (2006). PPM1A functions as a Smad phosphatase to terminate TGFbeta signaling. Cell 125, 915-928.

Lin, X., Liang, M., and Feng, X.H. (2000). Smurf2 is a ubiquitin E3 ligase mediating proteasome-dependent degradation of Smad2 in transforming growth factor-beta signaling. J Biol Chem 275, 36818-36822.

Lonn, P., van der Heide, L.P., Dahl, M., Hellman, U., Heldin, C.H., and Moustakas, A. (2010). PARP-1 attenuates Smad-mediated transcription. Mol Cell 40, 521-532.

Miles, W.O., Jaffray, E., Campbell, S.G., Takeda, S., Bayston, L.J., Basu, S.P., Li, M., Raftery, L.A., Ashe, M.P., Hay, R.T., et al. (2008). Medea SUMOylation restricts the signaling range of the Dpp morphogen in the Drosophila embryo. Genes Dev 22, 2578-2590.

Millan, J.L. (2013). The role of phosphatases in the initiation of skeletal mineralization. Calcif Tissue Int 93, 299-306.

Mornet, E., Stura, E., Lia-Baldini, A.S., Stigbrand, T., Menez, A., and Le Du, M.H. (2001). Structural evidence for a functional role of human tissue nonspecific alkaline phosphatase in bone mineralization. The Journal of biological chemistry 276, 3117131178.

Nakao A, I.T., Souchelnytskyi S, et al. (1997). TGF-beta receptor-mediated signalling through Smad2, Smad3 and Smad4. The EMBO Journal 16(17), 5353-5362. .

Rockey, D.C., Bell, P.D., and Hill, J.A. (2015). Fibrosis--a common pathway to organ injury and failure. The New England journal of medicine 372, 1138-1149.

Romanelli, F., Corbo, A., Salehi, M., Yadav, M.C., Salman, S., Petrosian, D., Rashidbaigi, O.J., Chait, J., Kuruvilla, J., Plummer, M., et al. (2017). Overexpression of tissue-nonspecific alkaline phosphatase (TNAP) in endothelial cells accelerates coronary artery disease in a mouse model of familial hypercholesterolemia. PloS one $12, \mathrm{e} 0186426$.

Serrano, A.L., and Munoz-Canoves, P. (2017). Fibrosis development in early-onset muscular dystrophies: Mechanisms and translational implications. Seminars in cell \& developmental biology 64, 181-190.

Shah, A.V., Birdsey, G.M., Peghaire, C., Pitulescu, M.E., Dufton, N.P., Yang, Y., Weinberg, I., Osuna Almagro, L., Payne, L., Mason, J.C., et al. (2017). The endothelial transcription factor ERG mediates Angiopoietin-1-dependent control of Notch signalling and vascular stability. Nature communications 8, 16002.

Sheen, C.R., Kuss, P., Narisawa, S., Yadav, M.C., Nigro, J., Wang, W., Chhea, T.N., Sergienko, E.A., Kapoor, K., Jackson, M.R., et al. (2015). Pathophysiological role of vascular smooth muscle alkaline phosphatase in medial artery calcification. Journal of bone and mineral research : the official journal of the American Society for Bone and Mineral Research 30, 824-836.

Tedesco, F.S., and Cossu, G. (2012). Stem cell therapies for muscle disorders. Current opinion in neurology 25, 597-603.

Ueha, S., Shand, F.H., and Matsushima, K. (2012). Cellular and molecular mechanisms of chronic inflammation-associated organ fibrosis. Frontiers in immunology 3, 71 .

Wood, L.K., Kayupov, E., Gumucio, J.P., Mendias, C.L., Claflin, D.R., and Brooks, S.V. (2014). Intrinsic stiffness of extracellular matrix increases with age in skeletal muscles of mice. J Appl Physiol (1985) 117, 363-369.

Zhu, H., Kavsak, P., Abdollah, S., Wrana, J.L., and Thomsen, G.H. (1999). A SMAD ubiquitin ligase targets the BMP pathway and affects embryonic pattern formation. Nature 400, 687-693. 
Zi, Z., Chapnick, D.A., and Liu, X. (2012). Dynamics of TGF-beta/Smad signaling. FEBS letters 586, 1921-1928.

Zi, Z., Feng, Z., Chapnick, D.A., Dahl, M., Deng, D., Klipp, E., Moustakas, A., and Liu, X. (2011). Quantitative analysis of transient and sustained transforming growth factor-beta signaling dynamics. Mol Syst Biol 7, 492.

\section{Figure Legends}

\section{Figure 1. TNAP activity under healthy, physiological conditions.}

(a) Frontal section of an adult (P30) mouse heart stained for alkaline phosphatase activity and eosin. Alkaline phosphatase activity is high small and medium size vessel (squares in Fig. 1a and Fig. 2b) and is also observed in some cardiomyocyte (Fig. 1c) (d) Confocal triple immunofluorescence of a small vessel stained with anti-VE Cadherin (green) and anti-NG2 (blue) antibodies and for AP activity (red). (e) RTPCR with probes specific for embryonic (A), intestinal (B), tissue non specific (C) alkaline phosphatase and for GAPDH (D). 1: adult liver; 2: adult intestine; 3: adult testis; 4:embryonic heart (E 11.5); 5: foetal heart (E 16.5); 6: neonatal heart (P1); 7: juvenile heart (P15); 8: adult heart (P90); 9 D16 (embryonic mesoangioblasts: Minasi et al. 2002); 10: negative control. (f) TNAP activity is maintained in adulthood. Tamoxifen was injected for 3 consecutive days in TNAP-Cre ${ }^{\text {ERT }} \times$ Rosa NGZ at P6,7,8 and the heart was collected at P60 (Dellavalle et al. 2011). A control injection of oil is shown in the inset. Scale bars: a $1 \mathrm{~mm}, \mathrm{~b}, \mathrm{c}, 50 \mu \mathrm{m} ; \mathrm{d}, 15 \mu \mathrm{m} ; \mathrm{f}, 0.5 \mathrm{~mm}$.

\section{Figure 2. TNAP is upregulated in different cell types in Ang II-induced fibrosis}

(a,b) Immunofluorescence for Tenascin C and TNAP in Sham and Ang II treated mice (c) Quantification of TNAP positive cells on both samples (mean \pm S.D., $n=5$ ). (d) RT-qPCR for Tnap in Sham and Ang II treated ventricle extracts (mean \pm S.D., $n=5$ ). Confocal images of Sham and Ang II treated heart sections stained for TNAP and PECAM1 (e, f); TNAP and Laminin (h, i); TNAP, PECAM1 and Vimentin (k, l). Insets show high magnifications of double positive cells. Quantifications of double positive cells are indicated in $\mathrm{g}, \mathrm{j}$ and $\mathrm{m}$ respectively (mean \pm S.D., $\mathrm{n}=3$ ). Scale bars: $20 \mu \mathrm{m}$. A two-tailed t-test was used to assess statistical significance: $* \mathrm{p}<0.05, * *$ $\mathrm{p}<0.01, * * * \mathrm{p}<0.001$.

\section{Figure 3. Deletion of Tgf- $\beta r 2$ in TNAP positive cells reduces Ang II induced} fibrosis in the heart.

(a, b) Confocal images of sections from Sham and Ang II treated heart labelled for TNAP and TGF-BRII. Arrows indicates double positive cell in the ventricle. High magnification images for separate channels shown below (a'-b','). (c) Schematic diagram of the experimental protocol. (d) RT-qPCR on Tgf- $\beta \mathrm{r} 2^{\mathrm{fl} / \mathrm{fl}}$ and Tnap ${ }^{\text {cre }}$; Tgf$\beta \mathrm{r} 2{ }^{\mathrm{fl} / \mathrm{fl}}$ heart ventricle extracts for the detection of Tgf- $\beta \mathrm{r} 2$ exon $4 / 5$ (mean \pm S.D., $\mathrm{n}=3$ ). Immunofluorescence for Tenascin $\mathrm{C}$ (e-g) and Tenascin $\mathrm{C}$ and PECAM1 (i-k) on Tnap ${ }^{\text {cre }} ;$ Tgf- $\beta r 2^{\text {fl/fl }}$ without Ang II, Tgf- $\beta r 2^{\mathrm{fl} / \mathrm{fl}}$ with Ang II and Tnap ${ }^{\text {cre }} ; \operatorname{Tgf}-\beta \mathrm{r} 2^{\mathrm{fl} / \mathrm{fl}}$ with Ang II heart ventricles sections. Percentage of interstitial (h) and vascular (l) fibrosis for the three groups. The quantification has been done on 6 different sections 
for each sample (mean \pm S.D., $\mathrm{n}=7$ and $\mathrm{n}=5$ for each group, respectively). Hematoxylin/eosin staining on heart sections from Tnap ${ }^{\text {cre }} ;$ Tgf- $\beta \mathrm{r} 2^{\mathrm{fl} / \mathrm{fl}}$ without Ang II (m), Tgf- $\beta \mathrm{r} 2^{\mathrm{fl} / \mathrm{fl}}$ with Ang II (n) and Tnap ${ }^{\mathrm{cre}} ;$ Tgf- $\beta \mathrm{r} 2^{\mathrm{fl} / \mathrm{fl}}$ with Ang II (o). (p) Heart and body weight ratio for the three groups. (q) Quantification of cardiomyocyte diameter for the three groups (mean \pm S.D., $n=4)$. $(r-t) R T-q P C R$ for Collagen1a2, Vimentin and Sma2 performed on Tnap ${ }^{\text {cre }} ;$ Tgf- $\beta \mathrm{r} 2^{\text {fl/fl }}$ without Ang II, Tgf- $\beta \mathrm{r} 2^{\text {fl/fl }}$ with Ang II and Tnap ${ }^{\text {cre }} ;$ Tgf- $\beta \mathrm{r} 2{ }^{\mathrm{fl} / \mathrm{fl}}$ with Ang II cDNA samples. Mean normalized fold changes \pm S.D., $\mathrm{n}=3$. Scale bars: $20 \mu \mathrm{m}$. Two-tailed test was used to assess statistical significance: $* \mathrm{p}<0.05, * * \mathrm{p}<0.01, * * * \mathrm{p}<0.001, * * * * \mathrm{p}<0.0001$.

\section{Figure 4. Deletion of Tgf- $\beta r 2$ in TNAP positive cells reduces skeletal muscle fibrosis in Sgca $^{-/-}$mice}

(a) Schematic diagram of the experimental protocol. (b) RT-qPCR on $\mathrm{Sgca}^{+/-}, \mathrm{Sgca}^{-/-}$ and $\mathrm{Sgca}^{-/-}$Tnap $^{\text {cre }}$;Tgf- $\beta \mathrm{r} 2{ }^{\mathrm{fl} / \mathrm{fl}}$ Tibialis Anterior for the detection of the exon $4 / 5$ of Tgf- $\beta \mathrm{r} 2$ (mean \pm S.D., $\mathrm{n}=3$ ). (c) Western blot for Tgf- $\beta \mathrm{r} 2$ on Tgf- $\beta \mathrm{r} 2$ fl/fl and Tnap ${ }^{\text {cre }}$ Tgf- $\beta \mathrm{r} 2{ }^{\mathrm{fl} / \mathrm{fl}}$ proteins extracts. Quantification of Tenascin $\mathrm{C}$ positive areas in $\mathrm{Sgca}^{+-}, \mathrm{Sgca}^{-/-}$and $\mathrm{Sgca}^{-/-}$Tnap ${ }^{\mathrm{cre}} ; \mathrm{Tgf}-\beta \mathrm{r} 2$ fl/fl Tibialis Anterior (TA) (d), Gastrocnemius (GA) (e) and Diaphragm (DIA) (f) muscles. The quantification has been done on 6 different sections for each sample. Staining for Tenascin C (g) and Collagen1a2 (h) on the TA of the three groups of mice. (i-k) RT-qPCR for Collagen1a2, Sma2 and Vimentin, performed on $\mathrm{Sgca}^{+/}, \mathrm{Sgca}^{-/-}$and $\mathrm{Sgca}^{-/}$ Tnap $^{\text {cre }} ;$ Tgf- $\beta r 2^{\text {fl/fl }}$ TA cDNA samples. Mean normalized fold change \pm S.D., $n=3$. (l) Muscle grip strength test on $\mathrm{Sgca}^{+/-}, \mathrm{Sgca}^{-/-}$and $\mathrm{Sgca}^{-/-} \mathrm{Tnap}^{\mathrm{cre}} ; \mathrm{Tgf}-\beta \mathrm{rr}{ }^{\mathrm{fl} / \mathrm{fl}}$ mice. Axis indicates the mean of immobile time over 50 second interval on upside-down wireframe ( \pm S.D.; $n=4)$. Scale bar represents $50 \mu \mathrm{m}$. A two-tailed t-test was used to assess statistical significance: $* \mathrm{p}<0.05, * * \mathrm{p}<0.01, * * * \mathrm{p}<0.001$.

\section{Figure 5. TNAP regulates SMAD2/3-dependent TGF- $\beta$ signaling}

(a,) Confocal images of TNAP and p-SMAD2/3 co-localization in Sham and Ang II treated heart sections. (b) Confocal images of intracellular co-localization of TNAP and SMAD2 in C2C12 cells transfected with EGFP-SMAD2 and mCherry-TNAP. (c) Proximity Ligation Assay (PLA) analysis of Myc-TNAP interaction with endogenous SMAD2 in C2C12 cells, untreated or treated with $5 \mathrm{ng} / \mathrm{ml}$ of TGF- $\beta 1$ for $3 \mathrm{~h}$; GFP was used as transfection control $(\mathrm{n}=3$ independent experiments). (d) Western blot analysis for SMAD2 and p-SMAD2/3 on cell lysate from primary cardiac fibroblasts treated with either $5 \mathrm{ng} / \mathrm{ml}$ of TGF- $\beta 1$ or $5 \mathrm{ng} / \mathrm{ml}$ of TGF- $\beta 1$ and TNAP inhibitor MLS-0038949 (200nM) for 1h; untreated cells were used as control. TNAP inhibition increases SMAD2/3 phosphorylation. (e, f) Immunofluorescence analysis for GFP and TNAP activity in C2C12 cells transfected with Myc-TNAP and GFP plasmids. C2C12 transfected only with GFP were used as control. (g) Western blot analysis for SMAD2 and p-SMAD2/3 on C2C12 cells transfected with Myc-TNAP and GFP plasmids, treated or untreated with $5 \mathrm{ng} / \mathrm{ml} \mathrm{TGF}-\beta 1$ for $3 \mathrm{~h}$; $\mathrm{C} 2 \mathrm{C} 12$ transfected only with GFP plasmid were used as control. Myc-TNAP overexpression leads to reduced SMAD phosphorylation. (h) Densitometric analysis of the Western Blot shown in (g). Grey bars: phopho-SMAD; Black bars: SMAD. Each bar represent the value normalised to Vinculin and plotted in relation to control SMAD, arbitrarily set at 1. (i) 
RT-qPCR for Fibronectin, Collagen1a2 and Tenascin C performed on cDNA samples from $\mathrm{C} 2 \mathrm{C} 12$ transfected with Myc-TNAP and GFP plasmids treated with either 5 $\mathrm{ng} / \mathrm{ml}$ of TGF- $\beta 1$ for $3 \mathrm{~h}$ or untreated; C2C12 transfected only with GFP were used as control. Normalized fold changes (mean \pm S.D.) are shown in $\mathrm{h}(\mathrm{n}=3$ independent experiments). Scale bars: $20 \mu \mathrm{m}$. Two-tailed t-test was used to assess statistical significance: $* \mathrm{p}<0.05, * * \mathrm{p}<0.01, * * * \mathrm{p}<0.001$. 
Figure 1

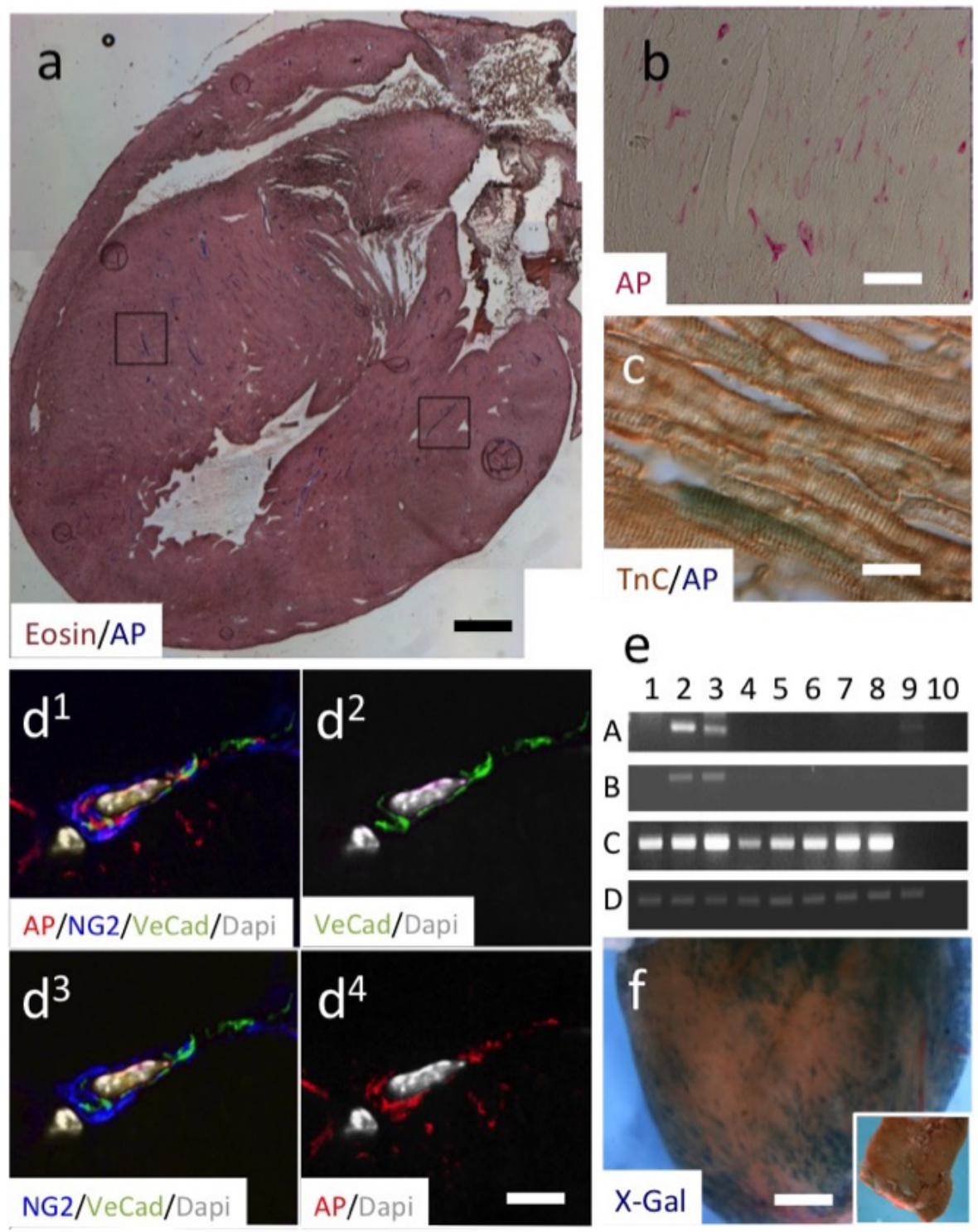



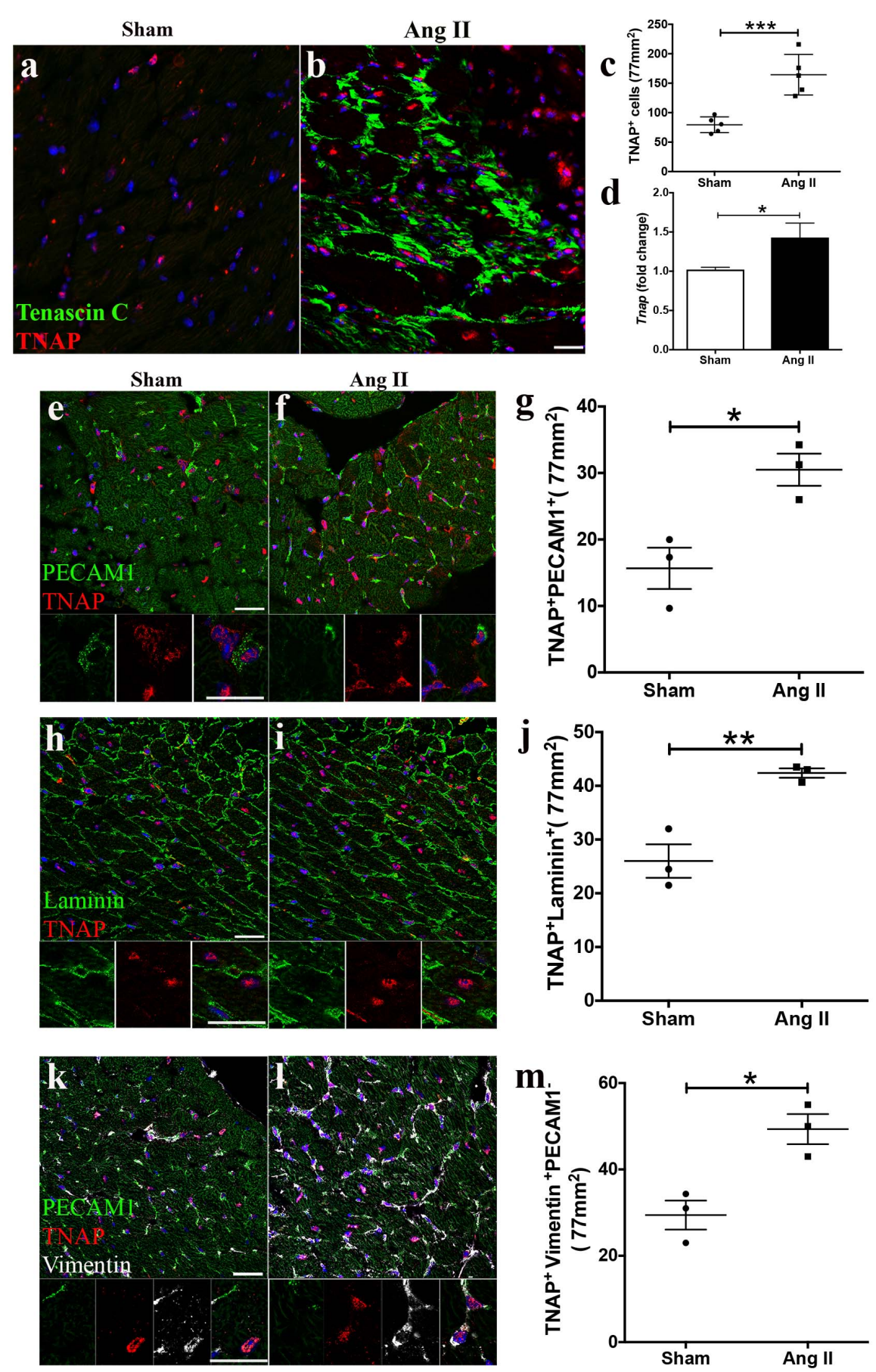

Figure 2 
Sham

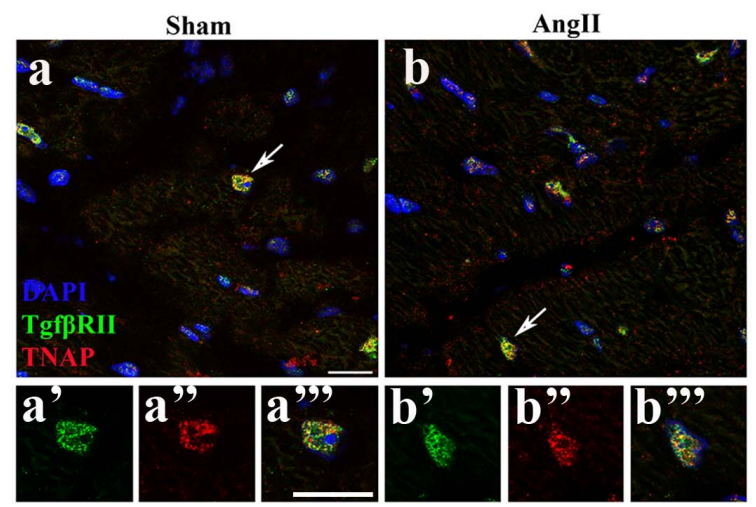

c

$\operatorname{Tgf} \beta r 2^{n / n}$

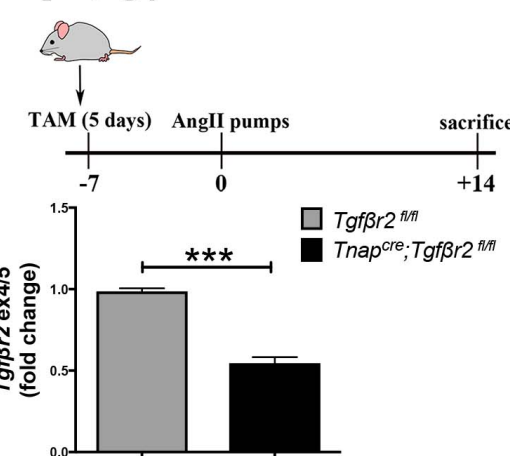

- Tnapcre TgfßRIfflt

TfBRllith + Ang
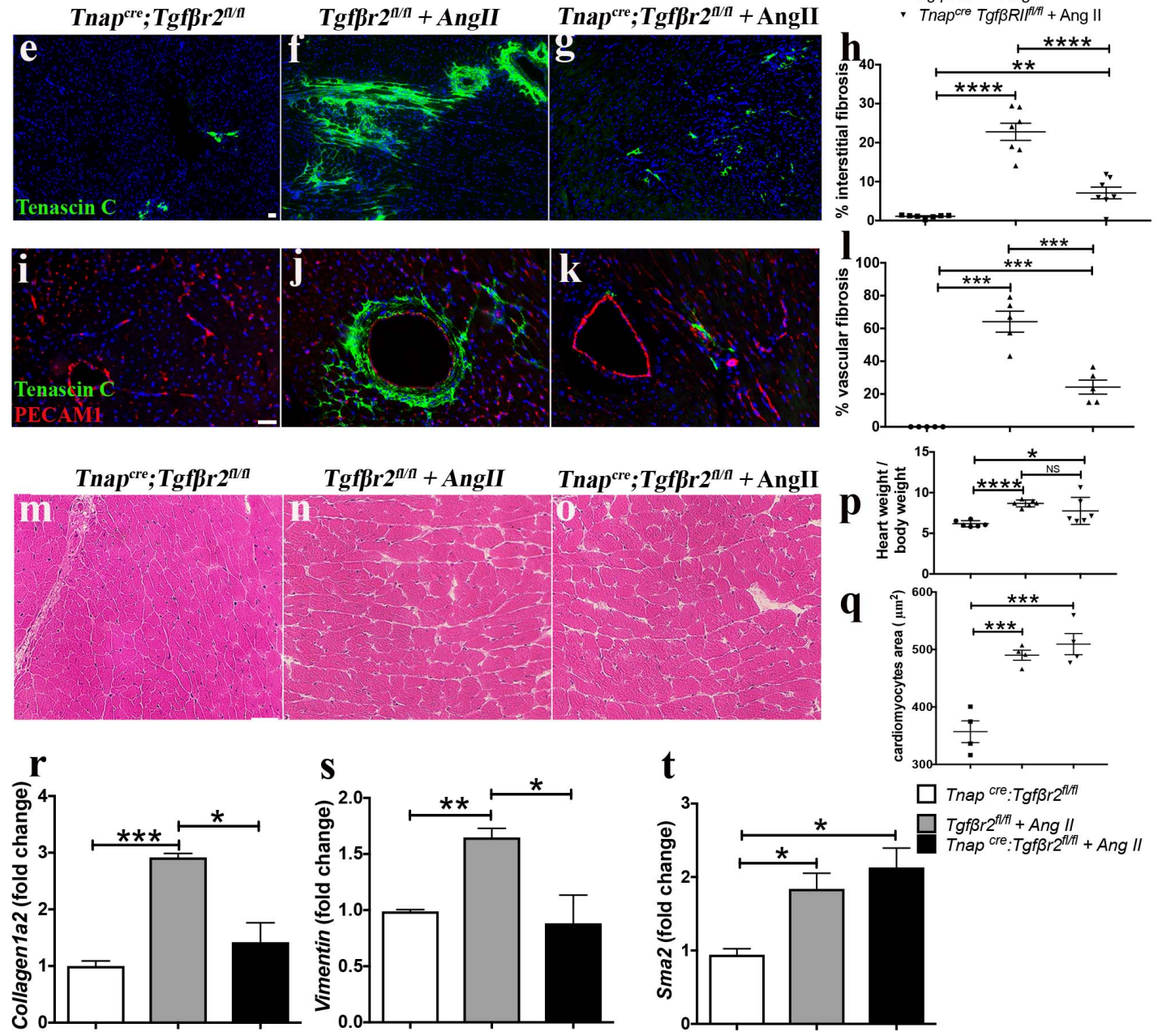
P

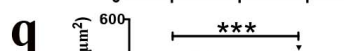

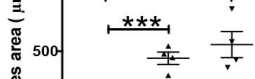
号 产 400 :
Figure 3 
a

$\mathrm{Sgca}^{-1}$;

$\operatorname{Tnap}^{\text {re }} ; \operatorname{Tgffr}^{2 / / 1}$

2

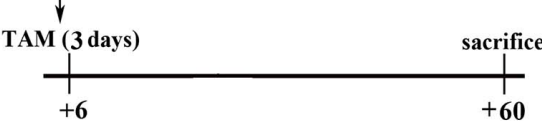

d

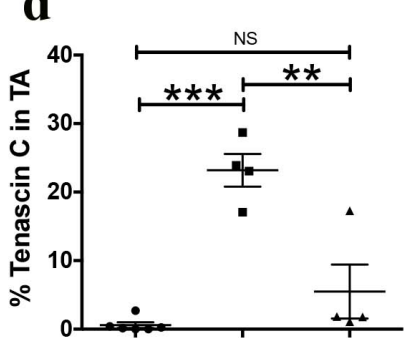

$\mathrm{Sgca}^{+-} \operatorname{Tnap}^{\text {cre }} ; \operatorname{Tgf\beta r}^{\mathrm{II/n}}$ b $\quad \mathrm{Sgca}^{\mathrm{Sg} \mathrm{sga}^{-1}}$

Sgca ${ }^{-/-} ;$Tnap ${ }^{\text {cre }}:$ TgfBr $2^{\text {flffl }}$

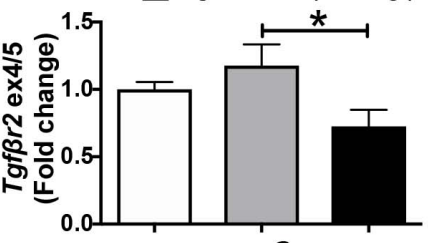

c

啇

ฟั

Tgfir2 $\rightarrow$
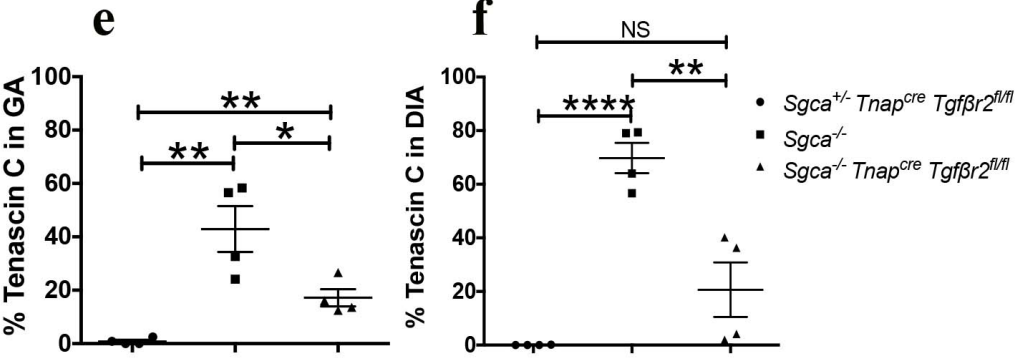

$\operatorname{Sgca}^{-1-} \operatorname{Tnap}^{\text {cre }} ; \operatorname{Tgf\beta r} 2^{\text {II/n }}$

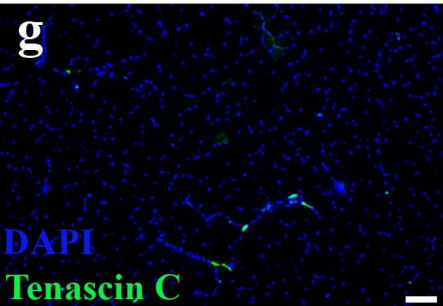

Sgca

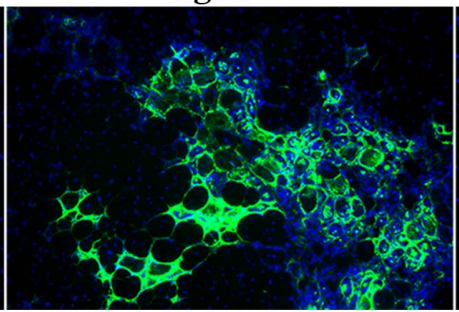

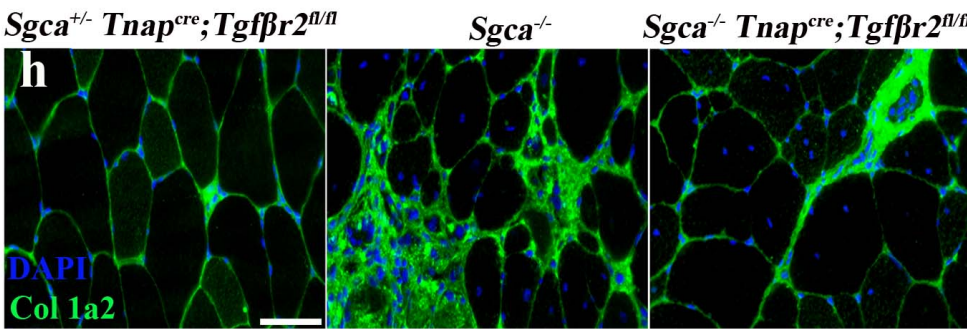
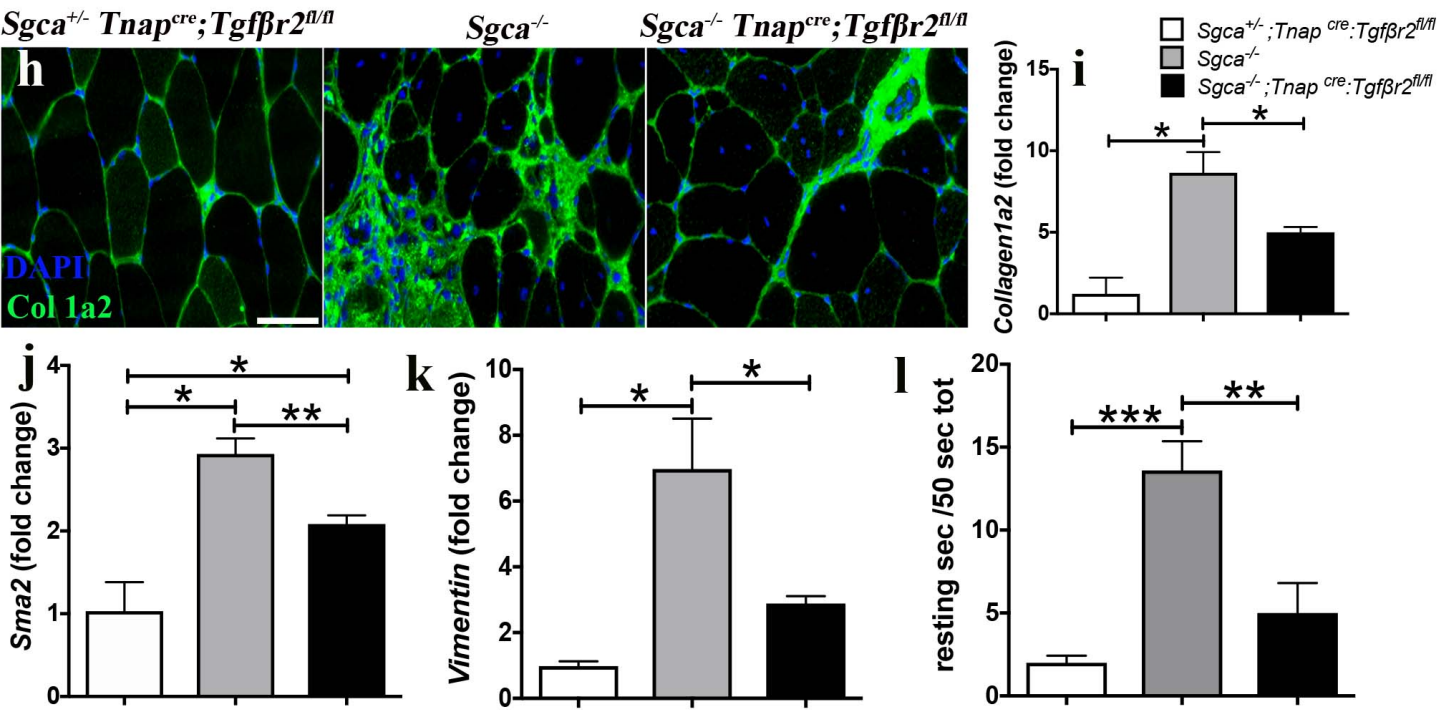
Figure 5
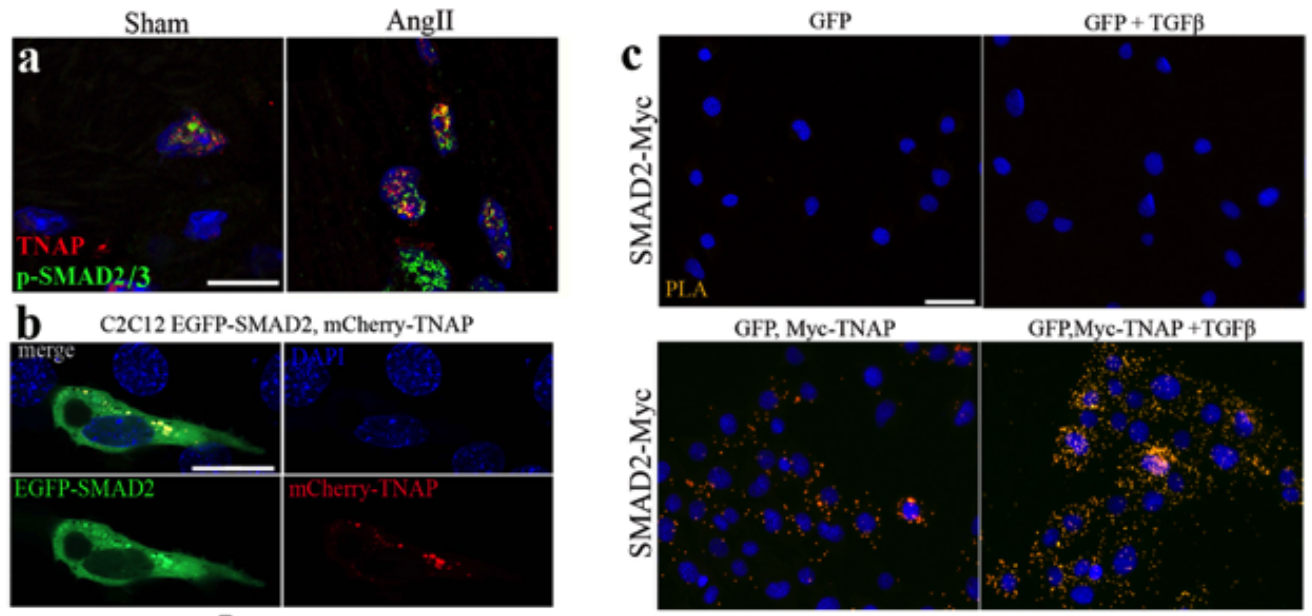

d
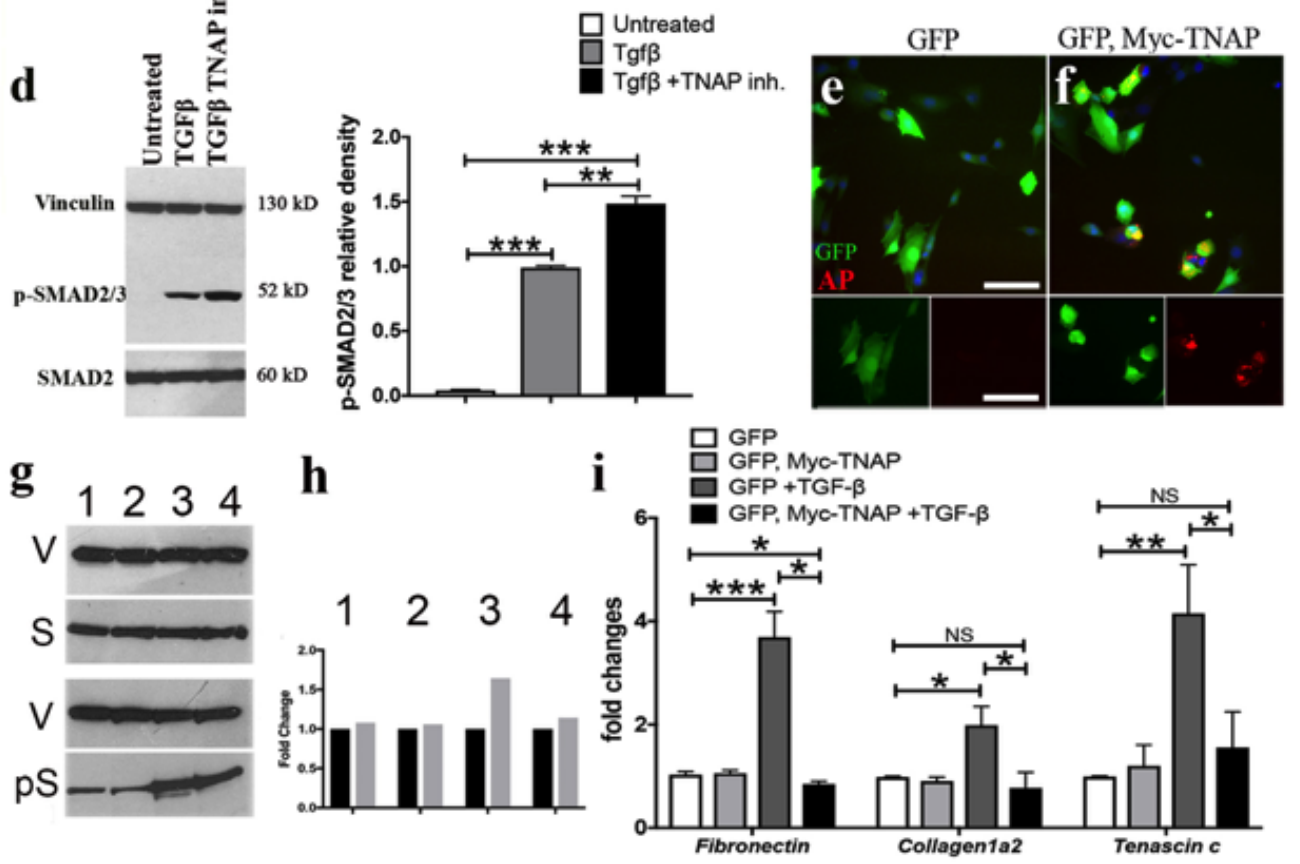